\title{
Prevalence of Hypertension and Its Associated Factors among Indonesian Adolescents
}

\author{
Andra Kurnianto $\mathbb{D}^{1},{ }^{1}$ Deni Kurniadi Sunjaya, ${ }^{2}$ Fedri Ruluwedrata Rinawan, \\ and Dany Hilmanto ${ }^{3}$ \\ ${ }^{1}$ Faculty of Medicine, Universitas Sriwijaya, Palembang, Indonesia \\ ${ }^{2}$ Department of Public Health, Faculty of Medicine, Universitas Padjadjaran, Bandung, Indonesia \\ ${ }^{3}$ Division of Pediatric Nephrology, Department of Child Health, Faculty of Medicine, Universitas Padjadjaran, \\ Bandung, Indonesia
}

Correspondence should be addressed to Andra Kurnianto; dr.andrak@gmail.com

Received 18 May 2020; Revised 28 July 2020; Accepted 2 September 2020; Published 16 September 2020

Academic Editor: Tomohiro Katsuya

Copyright (C) 2020 Andra Kurnianto et al. This is an open access article distributed under the Creative Commons Attribution License, which permits unrestricted use, distribution, and reproduction in any medium, provided the original work is properly cited.

\begin{abstract}
Background. Given that hypertension in adulthood has its onset in childhood, it is not surprising that the prevalence of hypertension among adolescents has also increased in recent years. However, there are limited data on the prevalence of hypertension and also the new AAP guideline has not yet been applied to the Indonesian adolescent population. Thus, this study aimed to evaluate the prevalence of hypertension using the new AAP guideline and to assess the occurrence of its associated factors among Indonesian adolescents. Methods. This was a cross-sectional study conducted at twelve senior high schools in Palembang, South Sumatera, Indonesia, from June to December 2019. The study included adolescents aged 13 to 18 years old. Anthropometric measurements were obtained. Multiple logistic regression was used to assess the risk factors most associated with hypertension among adolescents, and then an equation model was created. The prevalence of hypertension was evaluated, together with several factors such as age group, sex, ethnicity, family history of hypertension, nutritional status, physical activity, perceived stress, sleep duration, nutritional intake, and smoking. Results. In total, 1200 adolescents aged $15.9 \pm 0.99$ years were evaluated. The prevalence of hypertension and elevated blood pressure among adolescents was $8 \%$ and $12.2 \%$, respectively. There were significant associations between sex, family history of hypertension, hypertensive father, nutritional status, physical activity, perceived stress, and hypertension among Indonesian adolescents $(p<0.05)$. Stress was the most powerful risk factor of hypertension with an odds ratio of 5.83 (95\% confidence interval 2.91-11.6). Conclusions. Nowadays, the prevalence of hypertension among Indonesian adolescents is quite high. This may be caused by lifestyle or behavior changes among adolescents. Sex, family history of hypertension, nutritional status, physical activity, and perceived stress influenced the $27 \%$ hypertension prevalence rate among Indonesian adolescents, particularly in Palembang, South Sumatera. In order to decrease the prevalence of hypertension in adults, concern about lifestyle or behavior changes and hypertension among adolescents should be given.
\end{abstract}

\section{Introduction}

Hypertension is the most common noncommunicable disease, which persists as a significant health risk globally $[1,2]$. In the last decade, its prevalence rate has increased by $5.2 \%$ worldwide $[2,3]$. In Indonesia, the prevalence rate of hypertension has dramatically increased from $25.8 \%$ in 2013 to $34.1 \%$ in $2018[4,5]$. Blood pressure (BP) levels in adulthood have been found to be significantly correlated with the BP levels in childhood [6]. As a predictor of hypertension in adulthood, the BP level during adolescence is more reliable than that during childhood [7]. The American Academy of Pediatrics (AAP) issued a new clinical practice guideline in 2017 for defining hypertension in children and adolescents that aligns with the new American Heart Association (AHA) and American College of Cardiology (ACC) guidelines [8]. Unfortunately, the new AAP guideline has not yet been applied to the Indonesian adolescent 


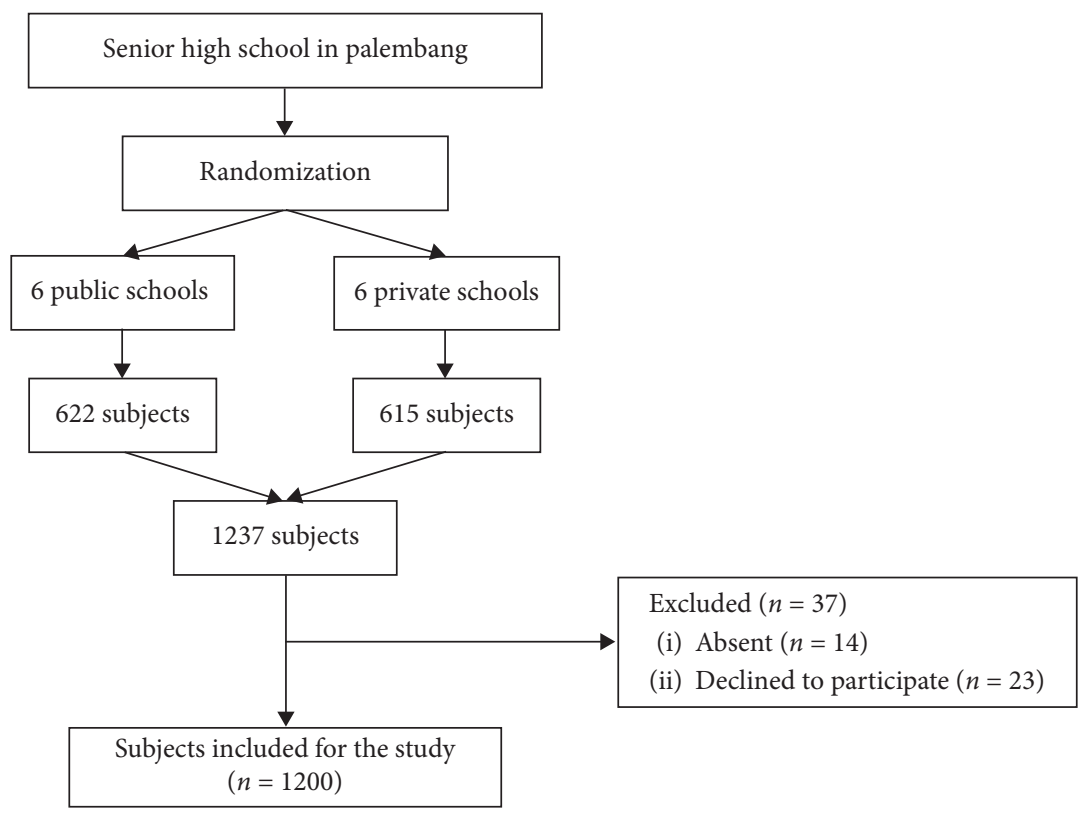

Figure 1: Study flow.

population. Given that hypertension in adulthood has its onset in childhood, it is not surprising that the prevalence of hypertension among adolescents has also increased in recent years $[9,10]$. However, there are limited data on the prevalence of hypertension and its associated factors among Indonesian adolescents particularly in Palembang, South Sumatera. Thus, this study aimed to evaluate the prevalence of hypertension using the new AAP clinical practice guideline and to assess the occurrence of its associated factors among Indonesian adolescents.

\section{Methods}

2.1. Subjects. This multicenter cross-sectional study was conducted from June to December 2019 at twelve senior high schools in Palembang, South Sumatera, Indonesia. The subjects were recruited using multistage random sampling. The selection of senior high schools, consisting of public and private, was based on cluster random sampling and then continued with simple random sampling from the total number of students. The study was approved by The Health Research Review Committee of Mohammad Hoesin Central Hospital and Sriwijaya University as well as The Research Ethics Committee Universitas Padjadjaran, Bandung. The study was conducted in accordance with National Ethical Guidelines on Health Research and its Supplements. A written informed consent from parents and verbal ascent of each study participant were obtained prior to recruitment. Adolescents aged 13 to 18 years old who had no congenital abnormalities and medication that potentially increases or decreases BP, had their BP and anthropometry measured, and completed all questionnaires were included in the study. The study flow is presented in Figure 1.
2.2. Study Protocol. The hypertension criteria used in this study were based on the new AAP clinical practice guideline for adolescents aged $\geq 13$ years old (normal BP: $<120 /<80$ mmHg; elevated BP: $120 /<80$ to $129 /<80 \mathrm{mmHg}$; Stage $1 \mathrm{HTN}$ : $130 / 80$ to $139 / 89 \mathrm{mmHg}$ and Stage $2 \mathrm{HTN}$ : $\geq 140 / 90 \mathrm{mmHg}$ ) [8]. The BP level was measured using Riester standard clinical aneroid sphygmomanometer and Littmann Classic II stethoscope with the subject in a sitting position and his/her right arm outstretched on the table. The measurement was performed thrice with a 5-minute interval and average when classifying BP. Body weight measurement was done using Seca digital scale with a capacity of $200 \mathrm{~kg}$ and accuracy of $0.1 \mathrm{~kg}$. Body height was measured using Seca microtoise with a capacity of $200 \mathrm{~cm}$ and an accuracy of $0.1 \mathrm{~cm}$. The subjects were asked to take off their footwear and hair accessories at the time of measurement.

The nutritional status or body mass index-for-age was assessed using World Health Organization (WHO) growth charts (Software WHO AnthroPlus version 1.0.4) and classified as obese (above $+2 \mathrm{SD}$ or more than or equal to the 97 th percentile), overweight (above $+1 \mathrm{SD}$ or 85 th to less than the 97 th percentile), and normoweight (above $-2 \mathrm{SD}$ to $+1 \mathrm{SD}$ or 15 th to less than the 85 th percentile) [11]. WHO AnthroPlus is a software for the global application of the WHO Reference 2007 for 5-19 year olds to monitor the growth of school-age children and adolescents [11].

Physical activity level was obtained using the Physical Activity Questionnaire for Adolescents (PAQ-A) and classified as less active ( 1 to 2 points) and active ( 3 to 5 points) [12]. PAQ-A is a self-administered 7-day recall questionnaire that assesses participation in different physical activities, as well as activities during physical education classes, 
TABLE 1: Sociodemographic characteristics.

\begin{tabular}{lc}
\hline Characteristics & $N(\%)$ \\
\hline Age (years old) & $198(16.4)$ \\
14 & $416(34.7)$ \\
15 & $380(31.7)$ \\
16 & $206(17.2)$ \\
17 & \\
\hline Sex & $442(36.8)$ \\
Male & $758(63.2)$ \\
Female & \\
\hline Ethnicity & $872(72.7)$ \\
Palembang & $328(27.3)$ \\
Others & $444(37)$ \\
\hline Family history of hypertension & $756(63)$ \\
Present & \\
Absent & $260(21.7)$ \\
\hline Hypertensive father & $940(78.3)$ \\
Yes & \\
No & $248(20.7)$ \\
\hline Hypertensive mother & $952(79.3)$ \\
Yes &
\end{tabular}

during lunch breaks, after school, in the evenings, and at weekends [12]. Perceived stress was determined using the Perceived Stress Scale (PSS) and classified as perceived stress (14 to 40 points) and not perceived stress (0 to 13 points) [13]. PSS is the most widely used tool for measuring the perception of stress, with 10 items asking about feelings and thoughts during the last month [13].

Dietary intake data were obtained using three consecutive 24-hour dietary recalls [14] and defined using Recommended Dietary Allowances (RDA) for Indonesian adolescents aged 13 to 18 years old based on Indonesia Ministry of Health [15]. The 24-hour dietary recall method provides comprehensive quantitative information on individual diets by asking about food and beverages consumed during the previous 24-hour period [14]. Sodium intake was classified as high (more than 1.5 grams) and moderate (1.5 grams), fat intake classified as high (male: more than 89 grams; female: more than 71 grams) and moderate (male: 83 to 89 grams; female: 71 grams), fiber intake classified as low (male: less than 35 grams; female: less than 30 grams) and moderate (male: 35 to 37 grams; female: 30 grams), potassium intake classified as low (less than 4.7 grams) and moderate (4.7 grams), calcium intake classified as low (less than 1.2 grams) and moderate (1.2 grams) [15]. Family history of hypertension, smoking, and sleep duration were obtained using a self-report questionnaire. Sleep duration was classified as inadequate (less than 7 hours per night) and adequate (more than or equal to 7 hours per night) [16]. All the validated questionnaires were in Indonesian language (bahasa).

2.3. Statistical Analysis. The frequency distribution, mean, standard deviation, odds ratio, and 95\% confidence interval were used for descriptive analysis of the data. Variables with $p$ value smaller than 0.25 can be included for further
TABle 2: Lifestyle risk factors.

\begin{tabular}{|c|c|}
\hline Risk factors & $N(\%)$ \\
\hline $\begin{array}{l}\text { Nutritional status } \\
\text { Obese } \\
\text { Overweight } \\
\text { Normoweight }\end{array}$ & $\begin{array}{c}116(9.7) \\
156(13) \\
928(77.3)\end{array}$ \\
\hline $\begin{array}{l}\text { Physical activity } \\
\text { Less active } \\
\text { Active }\end{array}$ & $\begin{array}{l}600(50) \\
600(50) \\
\end{array}$ \\
\hline $\begin{array}{l}\text { Perceived stress } \\
\text { Yes } \\
\text { No }\end{array}$ & $\begin{array}{l}382(31.8) \\
818(68.2) \\
\end{array}$ \\
\hline $\begin{array}{l}\text { Sleep duration } \\
\text { Inadequate } \\
\text { Adequate } \\
\end{array}$ & $\begin{array}{l}940(78.3) \\
260(21.7) \\
\end{array}$ \\
\hline $\begin{array}{l}\text { Dietary intake sodium } \\
\text { High } \\
\text { Moderate }\end{array}$ & $\begin{array}{c}80(6.7) \\
1120(93.3) \\
\end{array}$ \\
\hline $\begin{array}{l}\text { Fat } \\
\text { High } \\
\text { Moderate } \\
\end{array}$ & $\begin{array}{l}396(33) \\
804(67) \\
\end{array}$ \\
\hline $\begin{array}{l}\text { Fiber } \\
\text { Low } \\
\text { Moderate } \\
\end{array}$ & $\begin{array}{c}1192(99.3) \\
8(0.7) \\
\end{array}$ \\
\hline $\begin{array}{l}\text { Potassium } \\
\text { Low } \\
\text { Moderate } \\
\end{array}$ & $\begin{array}{c}1188(99) \\
12(1) \\
\end{array}$ \\
\hline $\begin{array}{l}\text { Calcium } \\
\text { Low } \\
\text { Moderate } \\
\end{array}$ & $\begin{array}{c}1176(98) \\
24(2)\end{array}$ \\
\hline $\begin{array}{l}\text { Smoking } \\
\text { Yes } \\
\text { No }\end{array}$ & $\begin{array}{c}40(3.3) \\
1160(96.7) \\
\end{array}$ \\
\hline $\begin{array}{l}\text { Smoking father } \\
\text { Yes } \\
\text { No }\end{array}$ & $\begin{array}{l}568(47.3) \\
632(52.7)\end{array}$ \\
\hline $\begin{array}{l}\text { Smoking mother } \\
\text { Yes } \\
\text { No }\end{array}$ & $\begin{array}{c}16(1.3) \\
1184(98.7)\end{array}$ \\
\hline
\end{tabular}

multivariable analysis. Multiple logistic regression was used to assess the risk factors most associated with hypertension among adolescents, and then an equation model was created. The significance level was set at $p<0.05$.

\section{Results}

The sociodemographic characteristics and lifestyle risk factors of the subjects are presented in Tables 1 and 2. There were 1200 adolescents consisting of $442(36.8 \%)$ males and 758 (63.2\%) females. Most of them in the midadolescence, that is, between 14 and 16 years old (82.8\%). The ethnicity of a majority of the subjects was Palembangnese (72.7\%), and only $37 \%$ had a family history of hypertension. Obese status and overweight status were found in $9.7 \%$ and $13 \%$ of subjects, respectively. Fifty percent of the subjects were less active, $31.8 \%$ had perceived stress, and $78.3 \%$ had inadequate sleep duration. The nutritional intake of the subjects consisted of low-fiber, low-potassium, and low-calcium diet 
TABLE 3: Blood pressure levels among adolescents.

\begin{tabular}{|c|c|c|c|}
\hline Blood pressure levels & $N(\%)$ & Systolic BP (mmHg) & Diastolic BP ( $\mathrm{mmHg})$ \\
\hline Normotension & $958(79.8)$ & \multirow{4}{*}{$109 \pm 10.6$} & \multirow{4}{*}{$72 \pm 8.5$} \\
\hline Elevated blood pressure & $146(12.2)$ & & \\
\hline Grade I hypertension & $84(7)$ & & \\
\hline Grade II hypertension & $12(1)$ & & \\
\hline
\end{tabular}

TABLE 4: Blood pressure levels according to sex characteristics.

\begin{tabular}{lcccc}
\hline Sex & Normotension & Elevated BP & Stage I HTN & Stage II HTN \\
\hline Male & $328(27.3)$ & $58(4.8)$ & $46(3.8)$ & $10(0.8)$ \\
Female & $630(52.5)$ & $88(7.4)$ & $38(3.2)$ & $2(0.2)$ \\
Total & $958(79.8)$ & $146(12.2)$ & $84(7)$ & $12(1)$ \\
\hline
\end{tabular}

(99.3\%, 99\%, and $98 \%$, respectively). Only $3.3 \%$ of the subjects were smokers; $47.3 \%$ had a smoking father and $1.3 \%$ had a smoking mother.

The prevalence rates of hypertension and elevated BP among Indonesian adolescents in Palembang were 8\% (7\% stage 1 and $1 \%$ stage 2 ) and $12.2 \%$, respectively (Table 3 ) with the average value of systolic BP $109 \pm 10.6 \mathrm{mmHg}$ and diastolic BP $72 \pm 8.5 \mathrm{mmHg}$. Table 4 shows blood pressure levels according to sex characteristics.

Table 5 presents the significant association between sex, family history of hypertension, hypertensive father, nutritional status, physical activity, perceived stress, and hypertension among Indonesian adolescents ( $p$ value $<0.05$ ). Variable hypertensive mother and smoking were also included for further multivariable analysis $(p$ value $<0.25)$.

Table 6 shows the final model of hypertension prevalence consisting of sex, family history of hypertension, nutritional status, physical activity, and perceived stress. The equation for hypertension prevalence was formulated. Hypertension prevalence $=-6.909+1.377($ Sex $)+0.994$ (family history of hypertension) +0.787 (nutritional status) +1.223 (physical activity) +1.763 (perceived stress). The aforementioned variables were found to influence the $27 \%$ hypertension prevalence rate among Indonesian adolescents in Palembang, South Sumatera.

\section{Discussion}

In this study, the prevalence rate of hypertension among adolescents in Palembang, South Sumatera was 8\%, which consisted of $7 \%$ stage I hypertension and $1 \%$ stage II hypertension. Our results indicated that the prevalence rate of hypertension in Palembang, South Sumatera, was higher than that of the Basic Health Research [4] in Indonesia and the study by Silva and Farias [17] in Brazil (5.3\% and 7.4\%, respectively) but lower than that of the study among adolescents by Pardede et al. [18] in Central Jakarta, Indonesia, and Bell et al. [19] in Houston, Texas, USA (9.6\% and 11.6\%, respectively). Pardede et al. [18] evaluated the prevalence of hypertension among Indonesian adolescents in Central Jakarta using different hypertension criteria based on the Fourth Report on the Diagnosis, Evaluation, and Treatment of High Blood Pressure in Children and Adolescent. The hypertension criteria used in this study were based on the new AAP clinical practice guideline that aligns with the new American Heart Association (AHA) and American College of Cardiology (ACC) guidelines [8]. Hence, blood pressure from childhood to adulthood can be traced.

With regard to sociodemographic factors, male adolescents had a 3.96 times higher risk of hypertension than female $(p<0.05)$. Even though the number of female adolescents was much higher in general population, the prevalence of hypertension among males was higher than female adolescents, which were $4.6 \%$ (3.8\% stage 1 and $0.8 \%$ stage 2 ) and $3.4 \%$ (3.2\% stage 1 and $0.2 \%$ stage 2$)$, respectively (Table 4). The adolescents with a family history of hypertension had a 2.7 times higher risk of hypertension than those without a family history of hypertension $(p<0.05)$. These findings were consistent with those of several previous studies. According to the results of the studies by Silva and Farias [17] and Singh et al. [20], male subjects and adolescents with a family history of hypertension significantly developed hypertension more than female subjects and adolescents without a family history of hypertension.

In terms of lifestyle risk factors, it appeared that the risk of hypertension was higher among adolescents with an obese/ overweight nutritional status who were physically less active than normoweight and physically active adolescents (2.19 and 3.39 , respectively). These results are in accordance with those of several other studies. The study by Singh et al. [20] also showed that obese/overweight and less active adolescents more likely had hypertension than normoweight and physically active adolescents. Sleep duration, smoking, and nutritional intake such as high-sodium and high-fat diet as well as low-fiber, low-potassium, and low-calcium diet surprisingly did not appear to be contributory to the risk factors in this group. This may be caused by several factors; that is, only a small number of adolescents were smoking and eating a high-sodium and high-fat diet (3.3\% and 6.7\%, respectively).

Multivariate analysis was used to assess the strongest risk factors that have a significant association with the occurrence of hypertension among adolescents. This study found, in agreement with the study by Shipp et al. [21] in South Texas, that stress was the most powerful risk factor of hypertension with an odds ratio of 5.83 (95\% confidence interval 2.91-11.6) although only a small number of adolescents (31.8\%) responded to be under some form of stress, termed as perceived stress. Stress may increase unhealthy coping behaviors, 
TABLE 5: Sociodemographic and lifestyle risk factors and hypertension among adolescents.

\begin{tabular}{|c|c|c|c|c|}
\hline \multirow{2}{*}{ Variable } & \multicolumn{2}{|c|}{ Hypertension } & \multirow{2}{*}{ OR $(95 \% \mathrm{CI})$} & \multirow{2}{*}{$p$ value } \\
\hline & Yes & No & & \\
\hline \multicolumn{5}{|l|}{ Age group (years old) } \\
\hline Midadolescence (14 to 16 ) & 84 & 910 & 1.49 & \multirow{2}{*}{0.432} \\
\hline Late adolescence (17 to 18 ) & 12 & 194 & $(0.61-3.60)$ & \\
\hline \multicolumn{5}{|l|}{$\operatorname{Sex}$} \\
\hline Male & 56 & 386 & 2.60 & \multirow{2}{*}{$0.002^{*}$} \\
\hline Female & 40 & 718 & $(1.42-4.74)$ & \\
\hline \multicolumn{5}{|l|}{ Ethnicity } \\
\hline Palembang & 68 & 804 & 0.90 & \multirow{2}{*}{0.738} \\
\hline Others & 28 & 300 & $(0.47-1.73)$ & \\
\hline \multicolumn{5}{|l|}{ Family history of hypertension } \\
\hline Present & 62 & 382 & 3.44 & \multirow{2}{*}{$0.000^{*}$} \\
\hline Absent & 34 & 722 & $(1.86-6.38)$ & \\
\hline \multicolumn{5}{|l|}{ Hypertensive father } \\
\hline Yes & 42 & 218 & 3.16 & \multirow{2}{*}{$0.000^{*}$} \\
\hline No & 54 & 886 & $(1.72-5.80)$ & \\
\hline \multicolumn{5}{|l|}{ Hypertensive mother } \\
\hline Yes & 30 & 218 & 1.84 & \multirow{2}{*}{$0.065^{* *}$} \\
\hline No & 66 & 886 & $(0.96-3.52)$ & \\
\hline \multicolumn{5}{|l|}{ Nutritional status } \\
\hline Obese/overweight & 36 & 236 & 2.20 & \multirow{2}{*}{$0.018^{*}$} \\
\hline Normoweight & 60 & 868 & $(1.18-4.09)$ & \\
\hline \multicolumn{5}{|l|}{ Physical activity } \\
\hline Less active & 70 & 530 & 2.91 & \\
\hline Active & 26 & 574 & $(1.51-5.63)$ & $0.001^{*}$ \\
\hline Perceived stress & & & & \\
\hline Yes & 66 & 316 & 5.48 & $0 \Omega \cap 0 *$ \\
\hline No & 30 & 788 & $(2.90-10.3)$ & 0.000 \\
\hline Sleep duration & & & & \\
\hline Inadequate & 76 & 864 & 1.05 & \\
\hline Adequate & 20 & 240 & $(0.51-2.18)$ & 1.000 \\
\hline Dietary intake sodium & & & & \\
\hline High & 2 & 78 & 0.28 & \\
\hline Moderate & 94 & 1026 & $(0.03-2.08)$ & 0.358 \\
\hline Fat & & & & \\
\hline High & 28 & 368 & 0.82 & \\
\hline Moderate & 68 & 736 & $(0.43-1.57)$ & 0.633 \\
\hline Fiber & & & & \\
\hline Low & 96 & 1096 & 0.91 & \\
\hline Moderate & 0 & 8 & $(0.89-0.94)$ & 1.000 \\
\hline Potassium & & & & \\
\hline Low & 96 & 1092 & 0.91 & \\
\hline Moderate & 0 & 12 & $(0.89-0.94)$ & 1.000 \\
\hline Calcium & & & & \\
\hline Low & 96 & 1080 & 0.91 & \\
\hline Moderate & 0 & 24 & $(0.89-0.94)$ & 0.612 \\
\hline Smoking & & & & \\
\hline Yes & 6 & 34 & 2.09 & \\
\hline No & 90 & 1070 & $(0.59-7.43)$ & $0.210^{* *}$ \\
\hline Smoking father & & & & \\
\hline Yes & 52 & 516 & 1.34 & \\
\hline No & 44 & 588 & $(0.74-2.43)$ & 0.367 \\
\hline Smoking mother & & & & \\
\hline Yes & 0 & 16 & 1.08 & \\
\hline No & 96 & 1088 & $(1.06-1.11)$ & 1.000 \\
\hline
\end{tabular}

${ }^{*} p$ value $<0.05 .{ }^{* *} p$ value $<0.25$. 
TABLE 6: Final model of hypertension prevalence.

\begin{tabular}{lcccc}
\hline Variable & $B$ & $p$ value & OR (95\% CI) & Nagelkerke $R$ square \\
\hline Sex & 1.377 & 0.000 & $3.96(2.01-7.80)$ & 0.27 \\
Family history of hypertension & 0.994 & 0.004 & $2.70(1.37-5.31)$ & $2.19(1.08-4.43)$ \\
Nutritional status & 0.787 & 0.028 & $3.39(1.66-6.93)$ & \\
Physical activity & 1.223 & 0.001 & $5.83(2.91-11.6)$ & \\
Perceived stress & 1.763 & 0.000 & 0.001 & \\
Constant & -6.909 & 0.000 & & \\
\hline
\end{tabular}

such as inadequate sleep; excessive food consumption; consumption of foods high in salt, sugar, and saturated fat; smoking; or consumption of alcohol that are associated with hypertension among adolescents [22].

In conclusion, the prevalence of hypertension among Indonesian adolescents is currently high. This may be caused by lifestyle or behavior changes. Sex, family history of hypertension, nutritional status, physical activity, and perceived stress influenced the $27 \%$ hypertension prevalence rate among Indonesian adolescents in Palembang, South Sumatera. In order to decrease the prevalence of hypertension in adults, concern about lifestyle or behavior changes and hypertension among adolescents should be given.

\section{Abbreviations}

AAP: American Academy of Pediatrics

ACC: American College of Cardiology

AHA: American Heart Association

BP: Blood pressure

CI: Confidence interval

HTN: Hypertension

OR: Odds ratio

PAQ-A: Physical Activity Questionnaire for Adolescents

PSS: $\quad$ Perceived Stress Scale

RDA: Recommended Dietary Allowances

WHO: World Health Organization.

\section{Data Availability}

The datasets used and analyzed during the current study are available from the corresponding author on reasonable request.

\section{Ethical Approval}

The study design was approved by the appropriate ethics review board.

\section{Consent}

All study participants provided informed consent.

\section{Conflicts of Interest}

The authors declare that they have no conflicts of interest.

\section{Authors' Contributions}

Andra Kurnianto and Dany Hilmanto conceptualized and designed the study and also drafted and revised it. Deni
Kurniadi Sunjaya and Fedri Ruluwedrata Rinawan analyzed and interpreted of the data and also revised it. All authors approved the final version of the paper.

\section{Acknowledgments}

The authors thank the medical faculty students from Universitas Sriwijaya who made up the data collection team and the respondents who had participated in the study. The authors would like to thank Indonesia Endowment Fund for Education (Lembaga Pengelola Dana Pendidikan) for supporting this study.

\section{References}

[1] A. V. Chobanian, G. L. Bakris, H. R. Black et al., "The seventh report of the joint national committee on prevention, detection, evaluation, and treatment of high blood pressure," JAMA, vol. 28, pp. 2560-2569, 2003.

[2] M. J. Bloch, "Worldwide prevalence of hypertension exceeds 1.3 billion," Journal of the American Society of Hypertension, vol. 10, pp. 753-754, 2016.

[3] K. T. Mills, J. D. Bundy, T. N. Kelly et al., "Global disparities of hypertension prevalence and control: a systematic analysis of population-based studies from 90 countries," Circulation, vol. 134, pp. 441-450, 2016.

[4] Indonesia Ministry of Health, Basic Health Research (RISKESDAS) 2013, Agency for Health Research and Development, Jakarta, Indonesia, 2013.

[5] Indonesia Ministry of Health, Basic Health Research (RISKESDAS) 2018, Agency for Health Research and Development, Jakarta, Indonesia, 2018.

[6] W. Bao, S. A. Threefoot, S. R. Srinivasan, and G. S. Berenson, "Essential hypertension predicted by tracking of elevated blood pressure from childhood to adulthood: the Bogalusa heart study," American Journal of Hypertension, vol. 8, pp. 657-665, 1995.

[7] X. Chen and Y. Wang, "Tracking of blood pressure from childhood to adulthood: a systematic review and meta-regression analysis," Circulation, vol. 117, pp. 3171-3180, 2008.

[8] J. T. Flynn and B. E. Falkner, "New clinical practice guideline for the management of high blood pressure in children and adolescents," Hypertension, vol. 70, pp. 683-686, 2017.

[9] G. B. Luma and R. T. Spiotta, "Hypertension in children and adolescents," American Family Physician, vol. 73, pp. 15581568, 2006.

[10] J. T. Flynn, "High blood pressure in the young: why should we care?" Acta Paediatrica, vol. 107, pp. 14-19, 2018.

[11] World Health Organization, Software for Assessing Growth of the World's Children and Adolescents, World Health Organization, Geneva, Switzerland, 2009.

[12] K. C. Kowalski, P. R. E. Crocker, and N. P. Kowalski, "Convergent validity of the physical activity questionnaire for 
adolescents," Pediatric Exercise Science, vol. 9, pp. 342-352, 1997.

[13] R. Siqueira Reis, A. A. Ferreira Hino, and C. Romélio Rodriguez Añez, "Perceived stress scale," Journal of Health Psychology, vol. 15, pp. 107-114, 2010.

[14] G. S. Castell, L. Serra-Majem, and L. Ribas-Barba, "What and how much do we eat? 24-hour dietary recall method," Nutricion Hospitalaria, vol. 31, no. 3, pp. 46-48, 2015.

[15] Indonesia Ministry of Health, Peraturan Menteri Kesehatan Republik Indonesia Nomor 75 Tahun 2013 Tentang Angka Kecukupan Gizi Yang Dianjurkan Bagi Bangsa Indonesia, Indonesia Ministry of Health, Jakarta, Indonesia, 2013, http://gizi.depkes.go.id.

[16] M. Hirshkowitz, K. Whiton, S. M. Albert et al., "National Sleep Foundation's updated sleep duration recommendations," Sleep Health, vol. 1, no. 4, pp. 233-243, 2015.

[17] K. S. Silva and J. C. Farias Jr., "Risk factors associated with high blood pressure in adolescents," Revista Brasileira de Medicina do Esporte, vol. 13, pp. 213e-6e, 2007.

[18] S. O. Pardede, Yunilasari, and D. B. Setyanto, "Prevalence and factors that influence hypertension in adolescents in Central Jakarta," Journal of Clinical Medicine and Research, vol. 5, pp. 43-48, 2017.

[19] C. S. Bell, J. P. Samuel, and J. A. Samuels, "Prevalence of hypertension in children," Hypertension, vol. 73, pp. 148-152, 2019.

[20] A. K. Singh, A. Maheshwari, N. Sharma, and K. Anand, "Lifestyle associated risk factors in adolescents," Indian Journal of Pediatrics, vol. 73, pp. 901-906, 2006.

[21] E. M. Shipp, S. P. Cooper, L. Jiang, A. B. Trueblood, and J. Ross, "Influence of work on elevated blood pressure in Hispanic adolescents in South Texas," International Journal of Environmental Research and Public Health, vol. 16, pp. 1-12, 2019.

[22] V. S. S. Goncalves, T. F. Galvao, K. R. C. Andrade et al., "Prevalence of hypertension among adolescents: systematic review and meta-analysis," Revista de Saúde Pública, vol. 50, pp. 1-11, 2016. 